\title{
The Patient-Reported Outcome of Intra-Operative Direct Vision Pectoral Nerve Block for Postoperative Analgesia for Breast Surgery
}

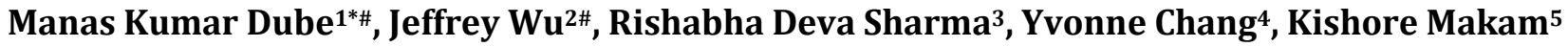 \\ ${ }^{1}$ Breast Surgery, King's Mill Hospital, Mansfield, UK \\ ${ }^{2}$ Internal Medicine, University Hospital of Coventry and Warwickshire, Coventry, UK \\ ${ }^{3}$ Breast Surgery, Royal United Bath Hospital, Bath, UK \\ ${ }^{4}$ Clinical Education, George Eliot Hospital, Nuneaton, UK \\ ${ }^{5}$ Breast Surgery, George Eliot Hospital, Nuneaton, UK \\ Email: ^manasdube@doctors.org.uk, jeffrey.wu@nhs.net, srishabha@gmail.com, yvonne.chang@nhs.net, \\ kishore.makam@geh.nhs.uk
}

How to cite this paper: Dube, M.K., Wu, J., Sharma, R.D., Chang, Y. and Makam, K. (2021) The Patient-Reported Outcome of Intra-Operative Direct Vision Pectoral Nerve Block for Postoperative Analgesia for Breast Surgery. Surgical Science, 12, 274-285.

https://doi.org/10.4236/ss.2021.128028

Received: July 19, 2021

Accepted: August 21, 2021

Published: August 24, 2021

Copyright $\odot 2021$ by author(s) and Scientific Research Publishing Inc. This work is licensed under the Creative Commons Attribution International License (CC BY 4.0).

http://creativecommons.org/licenses/by/4.0/

\begin{abstract}
Background and Aims: Pectoral nerve blocks gained increasing recognition for adequate postoperative pain relief following breast surgery. Traditionally, anaesthetist administered preoperatively under ultrasound guidance, which added significantly to the total procedure time. We studied the effectiveness of intraoperative direct vision pectoral nerve block and reduction of total theatre time. Methods: We provided questionnaires to the eligible patients who underwent a mastectomy and or axillary node clearance from August 2018 to May 2019. All the patients had an intra-operative pectoral 1 and serratus plane (Pecs) block. Participants documented pain score twice daily, episodes of nausea or vomiting and type and dose of analgesia for the first seven postoperative days. We compiled and grouped the results into postoperative days 1 - 2 and 3 - 7 for data analysis. Results: Patients reported generally low levels of pain, with a median pain score of 1.75 out of 10 for postoperative days 1 - 2 (IQR 4). The score decreased to 0.7 for days 3 - 7 postoperatively (IQR 3) suggesting that most patients had generally minimal levels of pain apart from a few outliers. The average injection time for PECs blocks was 5 minutes, significantly less than USS guided techniques of 20 - 30 minutes. Conclusions: Our data suggest that nerve blocks under direct vision offer satisfactory efficacy in postoperative analgesia with minimal nausea and vomiting. This is in addition to substantial benefits in operative efficiency and reduction of total procedure time.
\end{abstract}


Keywords

Breast Cancer, Analgesia, Pectoral Nerve Block

\section{Introduction}

Conventionally postoperative analgesia for breast surgery includes a multimodal approach with intra-operative infiltration of long-acting local anaesthetics like levobupivacaine, a combination of oral and intravenous paracetamol, nonsteroidal anti-inflammatory drugs (NSAIDS) and opioids when necessary. While general anaesthesia is still very commonly used for breast surgery, there has been a surge for regional techniques like pectoral nerve block 1 and serratus plane block (PECs block), paravertebral blocks and thoracic epidural techniques for analgesia, as well as a primary modality in patients who are high risk for anaesthesia [1]. Ultrasound-guided PECs block was described by Blanco et al. and has been very popular among anaesthetists [2] [3]. Although ultrasound-guided PEC1 and PEC2 blocks considered safe and provide significant intra and postoperative analgesia, there has been a case report of accidental infiltration to the brachial plexus resulting in short term numbness of the ipsilateral hand [4]. Single-shot PEC1 and PEC2 block and with or without further top-up in the postoperative period with the retained epidural catheters in both fascial planes also have been evaluated with randomised clinical trials [5] [6] [7]. Some of the studies have also revealed that pectoral and serratus plane block can reduce intraoperative fentanyl requirement, postoperative pain, postoperative morphine consumption, and postoperative nausea and vomiting (PONV) among those patients undergoing breast cancer surgery [8]. The Pecs block has been observed with fewer complexities and few complications when compared with thoracic paravertebral and thoracic epidural blocks in terms of analgesia quality [9] [10]. PEC II block has been efficient in providing pain relief among patients undergoing radical mastectomy. The present study has also presented the effectiveness of intraoperative direct vision pectoral nerve block and total theatre time reduction [11].

Ultrasound-guided PECs block was common practice in our hospital for the patients undergoing simple mastectomy with or without immediate reconstruction and for patients having axillary node clearance with wide local excision or mastectomy. When we audited our data regarding total theatre time, we had noticed that ultrasound-guided blocks required 20 - 30 minutes extra time. While direct vision intraoperative PECs blocks have been described by Goswami et al. and authors left the epidural catheter in the myofascial planes for postoperative analgesia, Haydon et al. described the techniques of direct vision serratus plane block (PEC2) for breast reconstruction using subpectoral implants [12] [13]. Several publications, including metanalysis, showed PECs blocks were associated with less postoperative opioid use leading to shortened recovery time [7] [14]. We endeavoured to inject long-acting local anaesthetics (levobupivacaine) in the 
myofascial plane (PEC1 and serratus plane) before wound closure under direct vision to decrease total time under general anaesthesia.

\subsection{Breast Innervation}

The sensory innervation of the breast is carried by the lateral and anterior cutaneous branches of the 2 nd through the 6th intercostal nerves. The sensation of the breast is derived from the dermatomes of breast development and is found to be segmented. The lateral mammary branches are responsible for supplying the skin covering of the breasts. The sensory anterior intercostal nerves are responsible for innervating the medial parts of the breast skin, while supraclavicular nerves do not contribute towards sensory innervation of skin covering in the breast [15]. The lateral branches of the 2nd intercostal nerve are responsible for the origin of the intercostobrachial nerve through the axilla to join the cutaneous nerve of the arm. The innervation of the nipple-areola complex and the central breast is derived from the anterior and lateral cutaneous branches of the 3rd, 4 th, and 5th intercostal nerves [16].

\subsection{Aims and Objectives}

To study the effectiveness of intraoperative direct vision pectoral nerve block to provide adequate postoperative analgesia and reduction of total theatre time.

\section{Method}

We conducted this prospective observational study following approval from the clinical governance department. The anaesthetic team was informed and agreed with the intraoperative surgeon-led blocks.

We obtained informed consent from all the patients before surgery. The anaesthetic team was informed and agreed with the intra-operative surgeon led blocks. Patients undergoing breast cancer surgery were eligible for the study. Age of entry was 18 or over. Mental capacity was assessed in the consent clinic prior to surgery. Information regarding the study were provided in the consent clinic and participation was voluntary.

All the patients undergoing simple mastectomy with or without axillary node clearance and all the patients who underwent axillary node clearance with or without simultaneous breast surgery from August 2018 to May 2019 were included.

Patients with arthritis, chronic back pain, fibromyalgia, or other chronic conditions, who were on regular non-opioid, steroids or opioid analgesics were excluded from the study. There was no age restriction in this study.

We explained the procedure to eligible patients at the consent clinic, and participation was voluntary. We distributed an anonymous questionnaire regarding postoperative pain in the visual analogue scale (VAS) to all the participants pre-operative with adequate explanation. Patients who had bilateral procedures 
were given two separate questionnaires to complete. Participants were asked to record VAS pain score twice daily, type and quantity of analgesia and any episode of postoperative nausea or vomiting (PONV). Out of 43 questionnaires we distributed, 36 were completed and returned. We compiled and analysed the data after grouping them as postoperative days $1-2$ as group 1 and postoperative day $3-7$ as group 2 .

\subsection{Techniques of PEC1 and PEC2 Block}

At the beginning of surgery patient's ipsilateral arm was abducted at an angle of 90 degrees on the operating table with the help of a multi-axis surgical arm board which is very standard practice for every breast surgery in our unit. For patients with restricted shoulder mobility, the angle was decreased to $70-80$ or less depending on individual circumstances. We performed PEC1 and 2 blocks after completion of mastectomy or axillary node clearance before the closure of the wound. Although injected under direct vision, we followed the principles of ultrasound guided PEC1 and 2 blocks described by Blanco et al. We injected 20 $\mathrm{ml}$ of $0.25 \%$ levobupivacaine in the myofascial plane between the pectoralis major and minor muscle with a depth of about $1-3 \mathrm{~cm}$ to block medial and lateral pectoral nerves (PEC1 block). We then injected another $20 \mathrm{ml}$ of $0.25 \%$ levobupivacaine in the interfacial plane between the pectoralis major muscle and the serratus anterior muscle in a depth of $3-6 \mathrm{~cm}$ aiming to block intercostal nerves 3 to 6 , the long thoracic and intercostobrachial nerves (PEC2 block). Fascia covering the serratus anterior was injected on the midaxillary line at the level of the $5^{\text {th }}$ intercostal space. Injection carried out in 4 increments of 5 $\mathrm{ml}$ each for both blocks. We took extreme care to avoid accidental injection to blood vessels or in the pleural cavity. The total procedure time was 5 minutes. We did not experience any procedure-related immediate or delayed complication.

\subsection{Statistical Method}

Descriptive statistics have been used for analysing the questionnaire after grouping them as postoperative days $1-2$ as group 1 and postoperative days $3-7$ as group 2. The mean and standard deviation has been used in descriptive statistics for analysing the result. The median and interquartile range was calculated for pain score.

\section{Results}

It was observed that out of 43 participants, 36 returned the completed questionnaire. The mean age was 65 years, and the median was 70 with a range of $33-84$ years (Table 1). Analysis of the type of surgery revealed that six patients had only axillary node clearance. Out of 25 patient who had a mastectomy, only two had bilateral mastectomies. Five patients had wide local excision with axillary node clearance (Table 2(a) and Table 2(b)). 
M. K. Dube et al.

Table 1. Age of participants.

\begin{tabular}{cccccc}
\hline & $\mathrm{N}$ & Minimum & Maximum & Mean & Std. Deviation \\
\hline Age at time of operation & 36 & 33.00 & 85.00 & 65.1944 & 15.33590 \\
Valid N (listwise) & 36 & & & & \\
\hline
\end{tabular}

Table 1: A total of 36 participants who had undergone surgery constituted study sample in this study. The mean age of the respondents was 65.19 years ranging from 33 to 85 years. The median age was 70 years.

Table 2. (a) Types of Operation; (b) Patients Demographics and analgesics requirement.

(a)

\begin{tabular}{|c|c|c|c|c|}
\hline Operations & Frequency & Percent & Valid Percent & Cumulative Percent \\
\hline Axillary node clearance & 1 & 2.8 & 2.8 & 2.8 \\
\hline Bilateral mastectomy + SLNB & 1 & 2.8 & 2.8 & 5.6 \\
\hline $\mathrm{L}$ therapeutic mastectomy and R risk-reducing mastectomy & 1 & 2.8 & 2.8 & 8.3 \\
\hline Left ANC & 2 & 5.6 & 5.6 & 13.9 \\
\hline Left Mastectomy + ANC & 1 & 2.8 & 2.8 & 16.7 \\
\hline Left mastectomy & 2 & 5.6 & 5.6 & 22.2 \\
\hline Left Mastectomy + ANC & 1 & 2.8 & 2.8 & 25.0 \\
\hline Left mastectomy + SLNB & 2 & 5.6 & 5.6 & 30.6 \\
\hline Left Mastectomy + SLNB & 1 & 2.8 & 2.8 & 33.3 \\
\hline Left mastectomy + SNLB & 1 & 2.8 & 2.8 & 36.1 \\
\hline Left Mastectomy and AN sampling & 1 & 2.8 & 2.8 & 38.9 \\
\hline Left mastectomy and reconstruction & 1 & 2.8 & 2.8 & 41.7 \\
\hline Left mastectomy and SLNB & 1 & 2.8 & 2.8 & 44.4 \\
\hline Left prophylactic Mastectomy & 1 & 2.8 & 2.8 & 47.2 \\
\hline Left total Mastectomy & 1 & 2.8 & 2.8 & 50.0 \\
\hline Left WLE + ANC & 2 & 5.6 & 5.6 & 55.6 \\
\hline Right ANC & 3 & 8.3 & 8.3 & 63.9 \\
\hline Right ANC + Inferior Cavity shave & 1 & 2.8 & 2.8 & 66.7 \\
\hline Right breast WLE + ANC & 1 & 2.8 & 2.8 & 69.4 \\
\hline Right completion mastectomy & 1 & 2.8 & 2.8 & 72.2 \\
\hline Right mastectomy & 1 & 2.8 & 2.8 & 75.0 \\
\hline Right mastectomy + ANC & 2 & 5.6 & 5.6 & 80.6 \\
\hline Right Mastectomy + ANC & 3 & 8.3 & 8.3 & 88.9 \\
\hline Right mastectomy + SLNB & 2 & 5.6 & 5.6 & 94.4 \\
\hline Right WLE + ANC & 2 & 5.6 & 5.6 & 100.0 \\
\hline Total & 36 & 100.0 & 100.0 & \\
\hline
\end{tabular}


(b)

\begin{tabular}{|c|c|c|c|c|c|c|c|c|c|}
\hline $\begin{array}{l}\mathrm{Ag} \\
\mathrm{e}\end{array}$ & Type of Surgery & $\begin{array}{l}\text { Form } \\
\text { returned }\end{array}$ & $\begin{array}{l}\text { Days of } \\
\text { analgesia }\end{array}$ & $\begin{array}{l}\text { Type of } \\
\text { analgesia }\end{array}$ & $\begin{array}{l}\text { Episodes } \\
\text { of nausea } \\
\text { and vomiting }\end{array}$ & $\begin{array}{l}\text { Nonopioid } \\
\text { analgscs } \\
(\text { day } 1-2)\end{array}$ & $\begin{array}{l}\text { Nonopioid } \\
\text { analgesics } \\
(\text { day } 3-7)\end{array}$ & $\begin{array}{l}\text { Opioid } \\
\text { analgscs } \\
(\text { day } 1-2)\end{array}$ & $\begin{array}{l}\text { Opioid } \\
\text { analgscs } \\
(\text { day } 3-7)\end{array}$ \\
\hline 69 & $\begin{array}{l}\text { Left Mastectomy and } \\
\text { AN sampling }\end{array}$ & Yes & 0 & nil & 0 & 0 & 0 & 0 & 0 \\
\hline 55 & $\begin{array}{l}\text { Right Mastectomy + } \\
\text { ANC }\end{array}$ & Yes & 7 & opioid & 0 & $\begin{array}{l}\text { Ibuprofen } 400 \mathrm{mg} \text {, } \\
\text { Pcm } 500 \mathrm{mg}\end{array}$ & $\begin{array}{l}\text { Paracetamol } 3 \\
\mathrm{~g}\end{array}$ & Codeine $30 \mathrm{mg}$ & Codeine $180 \mathrm{mg}$ \\
\hline 73 & $\begin{array}{l}\text { Right Mastectomy + } \\
\text { ANC }\end{array}$ & Yes & 7 & non-opioid & 0 & Paracetamol $4 \mathrm{~g}$ & $\begin{array}{l}\text { Paracetamol } 7 \\
\text { g }\end{array}$ & 0 & 0 \\
\hline 82 & $\begin{array}{l}\text { Right mastectomy }+ \\
\text { SLNB }\end{array}$ & Yes & 3 & non-opioid & 0 & 0 & 0 & 0 & 0 \\
\hline 79 & $\begin{array}{l}\text { Left mastectomy and } \\
\text { SLNB }\end{array}$ & Yes & 3 & opioid & 0 & Paracetamol $1.5 \mathrm{~g}$ & $\begin{array}{l}\text { Paracetamol } 1 \\
\mathrm{~g}\end{array}$ & Codeine $60 \mathrm{mg}$ & 0 \\
\hline 78 & $\begin{array}{l}\text { Left total } \\
\text { Mastectomy }\end{array}$ & Yes & 2 & non-opioid & 0 & Paracetamol $2 \mathrm{~g}$ & 0 & 0 & 0 \\
\hline 47 & $\begin{array}{l}\text { Left prophylactic } \\
\text { Mastectomy }\end{array}$ & Yes & 7 & non-opioid & 0 & $\begin{array}{l}\text { Paracetamol } 4 \mathrm{~g} \text {, } \\
\text { Ibuprofen } 1.6 \mathrm{~g}\end{array}$ & $\begin{array}{l}\text { Paracetamol } 5 \\
\mathrm{~g}\end{array}$ & 0 & 0 \\
\hline 70 & $\begin{array}{l}\text { Left Mastectomy + } \\
\text { ANC }\end{array}$ & Yes & 3 & non-opioid & 0 & Paracetamol $2.5 \mathrm{~g}$ & $\begin{array}{l}\text { Paracetamol } 1 \\
\text { g }\end{array}$ & 0 & 0 \\
\hline 61 & Right ANC & Yes & 0 & nil & 0 & 0 & 0 & 0 & 0 \\
\hline 77 & Left mastectomy & Yes & 0 & nil & 0 & 0 & 0 & 0 & 0 \\
\hline 48 & Right WLE + ANC & Yes & & non-opioid & 0 & Paracetamol $4 \mathrm{~g}$ & $\begin{array}{l}\text { Paracetamol } \\
10 \mathrm{~g}\end{array}$ & 0 & 0 \\
\hline 82 & $\begin{array}{l}\text { Axillary node } \\
\text { clearance }\end{array}$ & Yes & 3 & non-opioid & & Paracetamol $3.5 \mathrm{~g}$ & $\begin{array}{l}\text { Paracetamol } \\
500 \mathrm{mg}\end{array}$ & 0 & 0 \\
\hline 84 & $\begin{array}{l}\text { Left Mastectomy + } \\
\text { SLNB }\end{array}$ & Yes & 1 & non-opioid & 0 & 0 & 0 & 0 & 0 \\
\hline 61 & $\begin{array}{l}\mathrm{L} \text { therapeutic } \\
\text { mastectomy and } \\
\text { R prophylactic } \\
\text { mastectomy }\end{array}$ & Yes & 4 & non-opioid & 0 & Paracetamol $1.5 \mathrm{~g}$ & $\begin{array}{l}\text { Paracetamol } 1 \\
\text { g }\end{array}$ & 0 & 0 \\
\hline 81 & $\begin{array}{l}\text { Bilateral mastectomy } \\
+ \text { SLNB }\end{array}$ & Yes & 1 & non-opioid & 0 & Paracetamol $2 \mathrm{~g}$ & 0 & 0 & 0 \\
\hline 79 & Left ANC & Yes & 1 & non-opioid & 0 & Paracetamol $1 \mathrm{~g}$ & 0 & 0 & 0 \\
\hline 78 & Left ANC & Yes & 4 & opioid & 0 & Paracetamol $1 \mathrm{~g}$ & $\begin{array}{l}\text { Paracetamol } 1 \\
\mathrm{~g}\end{array}$ & Codeine $60 \mathrm{mg}$ & Codeine $60 \mathrm{mg}$ \\
\hline 41 & $\begin{array}{l}\text { Left mastectomy + } \\
\text { SLNB }\end{array}$ & Yes & 7 & non-opioid & 0 & $\begin{array}{l}\text { Paracetamol } 4 \mathrm{~g} \text {, } \\
\text { Ibuprofen } 1.2 \mathrm{~g}\end{array}$ & $\begin{array}{l}\text { Paracetamol } 5 \\
\mathrm{~g}, \text { Ibuprofen } \\
1.2 \mathrm{~g}\end{array}$ & & \\
\hline 72 & Right ANC & Yes & 0 & nil & 0 & 0 & 0 & 0 & 0 \\
\hline 65 & $\begin{array}{l}\text { Right ANC + } \\
\text { Inferior Cavity shave }\end{array}$ & Yes & 7 & non-opioid & 1 & Paracetamol $4 \mathrm{~g}$ & $\begin{array}{l}\text { Paracetamol } \\
10 \mathrm{~g}\end{array}$ & 0 & 0 \\
\hline 40 & Left WLE + ANC & Yes & 3 & non-opioid & 0 & Paracetamol $4 \mathrm{~g}$ & 0 & 0 & 0 \\
\hline 44 & Left mastectomy & Yes & 5 & opioid & 0 & $\begin{array}{l}\text { Paracetamol } 500 \\
\mathrm{mg}\end{array}$ & $\begin{array}{l}\text { Paracetamol } 2 \\
g\end{array}$ & $\begin{array}{l}\text { Codeine } 30 \mathrm{mg} \text {, } \\
\text { Oramorph } 10 \\
\mathrm{mg}\end{array}$ & 0 \\
\hline 34 & Right WLE + ANC & Yes & 2 & non-opioid & 0 & Paracetamol $2 \mathrm{~g}$ & 0 & 0 & 0 \\
\hline
\end{tabular}




\section{Continued}

\begin{tabular}{|c|c|c|c|c|c|c|c|c|}
\hline $\begin{array}{l}{ }_{83}^{\text {Right mastectomy }+} \\
\text { ANC }\end{array}$ & Yes & 0 & nil & 0 & 0 & 0 & 0 & 0 \\
\hline 78Right ANC & Yes & & nil & & 0 & 0 & 0 & 0 \\
\hline $\begin{array}{l}74 \text { Left mastectomy + } \\
\text { SLNB }\end{array}$ & Yes & 0 & nil & 0 & 0 & 0 & 0 & 0 \\
\hline 51 Left mastectomy and & Yes & 4 & nil & 0 & Paracetamol $2 \mathrm{~g}$ & $\begin{array}{l}\text { Paracetamol } 2 \\
\mathrm{~g}\end{array}$ & $\begin{array}{l}\text { Tramadol } 200 \\
\text { mg, Oramorph } \\
10 \mathrm{mg}\end{array}$ & $\begin{array}{l}\text { Tramadaol } 200 \\
\mathrm{mg}\end{array}$ \\
\hline $\begin{array}{l}72 \text { Right completion } \\
\text { mastectomy }\end{array}$ & Yes & 0 & nil & 0 & 0 & 0 & 0 & 0 \\
\hline 33Left WLE + ANC & Yes & 0 & nil & 0 & 0 & 0 & 0 & 0 \\
\hline 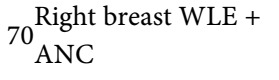 & Yes & 2 & non-opioid & 0 & Paracetamol $2 \mathrm{~g}$ & 0 & 0 & 0 \\
\hline $\begin{array}{l}\text { Right mastectomy + } \\
70 \text { SLNB }\end{array}$ & Yes & 7 & opioid & 1 & Paracetamol $6 \mathrm{~g}$ & $10 \mathrm{~g}$ & Codene $360 \mathrm{mg}$ & Codeine $600 \mathrm{mg}$ \\
\hline 61Right mastectomy & Yes & & non-opioid & 0 & Paracetamol $4 \mathrm{~g}$ & $\begin{array}{l}\text { Paracetamol } 10 \\
\mathrm{~g}\end{array}$ & $0_{0}$ & 0 \\
\hline 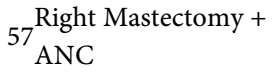 & Yes & 5 & non-opioid & 1 & Paracetamol $1 \mathrm{~g}$ & $\begin{array}{l}\text { Paracetamol } 4 \\
\text { g }\end{array}$ & 0 & 0 \\
\hline${ }^{85}{ }_{\text {SNLBx }}^{\text {Left mastectomy }+}$ & Yes & 0 & non-opioid & 1 & 0 & 0 & 0 & 0 \\
\hline $\begin{array}{l}65 \text { Right mastectomy + } \\
\text { ANC }\end{array}$ & Yes & 4 & non-opioid & 1 & Paracetamol $2.5 \mathrm{~g}$ & $\begin{array}{l}\text { Paracetamol } 3 \\
\mathrm{~g}\end{array}$ & 0 & 0 \\
\hline $\begin{array}{l}{ }^{48} \begin{array}{l}\text { Left Masectomy }+ \\
\text { ANC }\end{array}\end{array}$ & Yes & 7 & non-opioid & 0 & $5 \mathrm{~g}$ & 0 & 0 & 0 \\
\hline
\end{tabular}

On 1 - 2 postoperative day, the maximum percentage of the percentage of non-opioid analgesic used was $23.01 \%$ ranging from $0 \%$ to $75 \%$. On $3-7^{\text {th }}$ postoperative day, the percentage of non-opioid analgesic used was $11.04 \%$ ranging from $0 \%$ to $50 \%$. Mean opioid analgesic use on $1-2$ postoperative day was $4.09 \%$ ranging from $0 \%$ to $75 \%$, and $2.06 \%$ on postoperative $3-7$ ranging from 0 to $50 \%$ (Table 3). Mean VAS scores on 1 - 2 postoperative day were 2.08 and 1.58 on postoperative day $3-7$.

The most common non-opioid analgesic was paracetamol $1 \mathrm{gm}$ up to four times a day. Only $23 \%$ of patients used $4 \mathrm{~g}$ of paracetamol per 24 hours within the first two postoperative days, and $77 \%$ of the patients had $3 \mathrm{~g}$ or less. On analysing data of day 3 - 7 post-op days, only $11 \%$ were found to used $4 \mathrm{gm}$ of paracetamol per days, leaving $89 \%$ of patients' pain was controlled with less than optimum doses.

The most common opioid analgesic was codeine phosphate tablets used by five patients (14\%) in group 1 and 3 patients (8\%) in group 2 . The second most opioid analgesic was oral morphine solution $10 \mathrm{mg} / 10 \mathrm{ml}$ (Oramorph). Only two patients used as required oramorph along with paracetamol within the first two days of operation. There was no recorded use of oramorph in the $3-7$ days post-op group (Table 4). 
Following PEC1 and two blocks, patients experienced minimal pain which has been reflected in the mean pain score of 2.08 in the visual analogue scale ( $1-10$, where 1 was minimal pain or discomfort and 10 was very severe pain) in the postoperative day $1-2$. The mean pain score for postoperative day $3-7$ was 1.58. Median pain score for postoperative day $1-2$ was 1.75 and 0.7 for $3-7$ days (Table 5 and Figure 1). This indicated that apart from very few outliers, most patients had an incredibly low level of pain in the first week following surgery.

Table 3. Duration of analgesia requirement.

\begin{tabular}{cccccc}
\hline & N & Minimum & Maximum & Mean & Std. Deviation \\
\hline Days of analgesia & 36 & 00 & 7.00 & 2.9118 & 2.63275 \\
\hline
\end{tabular}

Table 4. Type of analgesia.

\begin{tabular}{ccccc}
\hline & Frequency & Percent & Valid Percent & Cumulative Percent \\
\hline nil & 10 & 27.8 & 27.8 & 27.8 \\
non-opioid & 21 & 58.3 & 58.3 & 86.1 \\
opioid & 5 & 13.9 & 13.9 & 100.0 \\
Total & 36 & 100.0 & 100.0 & \\
\hline
\end{tabular}

Table 5. Pain score.

\begin{tabular}{ccc}
\hline Post Operative days & Median Pain Score & Inter-quartile range \\
\hline Day1 & 2 & 4 \\
Day2 & 1 & 3 \\
Day3 & 0.5 & 3 \\
Day4 & 1 & 3 \\
Day5 & 0 & 3 \\
Day6 & 0 & 3 \\
Day7 & 0 & 3 \\
\hline
\end{tabular}

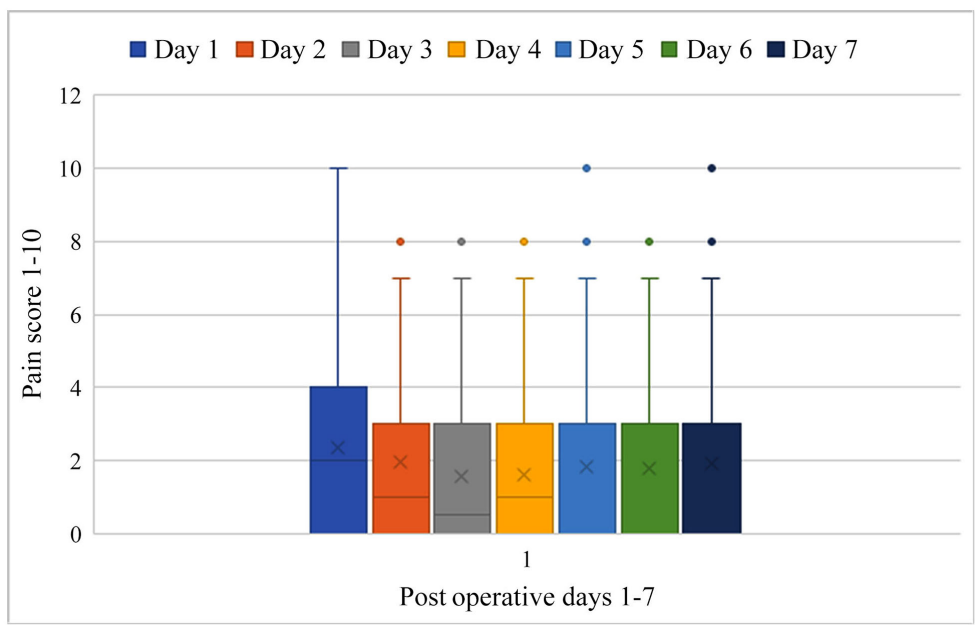

Figure 1. Box and whisker plot of pain score. 
Reported rates of nausea and vomiting were low, with a mean of only 0.15 episodes for all seven days, with most patients reporting no episodes.

As PECs block routinely administered in our hospital by the anaesthetists, 20 30 minutes timeslots allocated in the operating list for this procedure. When we performed the block intra-operatively, the average time was 5 minutes per patient, only saving valuable operating time significantly.

There were no incidences of postoperative haemorrhage or pneumothorax in our series.

\section{Discussion}

Pectoral nerve blocks have become an essential tool in reducing postoperative pain in breast surgery. Blanco described pecs block under ultrasound guidance in a group of 50 patients, who only required non-opioid analgesia postoperatively with rare exceptions [17].

Goswami et al. randomised patients to receive either PEC1 versus PEC2 block for postoperative pain relief while performing modified radical mastectomy and found PEC2 block provided better postoperative analgesia than PEC1 block [6].

Verskyck et al. recently performed a meta-analysis of current literature that found the Pecs II block reduced postoperative pain scores as well as postoperative opioid use. They concluded nerve blocks offered superior analgesic efficacy versus systemic analgesia alone and comparable efficacy to thoracic paravertebral block for breast surgery [18].

Many nerve blocks discussed in the literature are performed under ultrasound guidance. Less data is available for nerve blocks performed under direct vision. Hards et al. conducted a retrospective study of 16 patients who received serratus plane blocks under direct vision and found none reporting severe pain in recovery or day one postoperatively. This compared favourably with a control group receiving local anaesthetic wound infiltration alone, where multiple patients reported severe pain over the same time [19].

Haydon et al. described lateral pectoral nerve blocks under direct vision for all of their subpectoral breast reconstruction and augmentation procedures [13]. They report that before introducing this nerve block, they routinely provided paracetamol, NSAID, and patient-controlled fentanyl postoperatively. Following the adoption of routine nerve blocks under direct vision, they found most patients declined opioid analgesia, managing satisfactorily with non-opioid alone.

We did not face any difficulty in the administration of direct PECs blocks. There were no immediate or delayed procedure-related complications which made this procedure safe and effective. We were able to save at least 20 - 25 of operating time by avoiding ultrasound-guided blocks. Although we did not use any indwelling catheter, our results were comparable to the study described by Goswami et al., who used indwelling epidural catheter for further analgesia [6].

The main strength of our study was prospective data collection, communication with the patient before and after surgery and completion of data collection 
within the first two weeks of operation when patients still remember the event. The small sample size is one of the limitations and the other one being no randomisation

\section{Conclusion}

Pectoral nerve blocks have been very popular recently to provide postoperative analgesia. Ultrasound-guided blocks remain a common practice but require skilled anaesthetists and equipment. While ultrasound-guided techniques are highly effective, we found similar efficacy of postoperative analgesia with direct vision technique with no significant increase in the operative time or complications. The risk of block failure was also very minimal. The learning curve for the open technique was also shallow compared to the steep learning curve of ultrasound-guided PECs blocks. As breast surgeons are remarkably familiar with the anatomy of the pectoral region and the procedures, do not add up extra operative time direct vision PECs block may be particularly suitable for breast surgery.

\section{Funding}

The work did not require any separate funding

\section{CRediT Author Statement}

Manas Kumar Dube: Methodology, original draft preparation, final writing, reviewing, and editing.

Jeffrey $\mathrm{Wu}$ : Conceptualisation, data collection, original abstract and draft preparation, writing, reviewing and editing.

Rishabha Deva Shrama: Statistics, reviewing and editing.

Yvonne Chang: Data collection, corrections.

Kishore Makam: Conceptualisation, Supervision.

\section{Conflicts of Interest}

The authors declare no conflicts of interest regarding the publication of this paper.

\section{References}

[1] Nair, A.S., Kumar Sahoo, R., Ganapathy, M. and Mudunuri, R. (2015) Ultrasound Guided Blocks for Surgeries/Procedures Involving Chest Wall (Pecs 1, 2 and Serratus Plane Block). Anaesthesia, Pain \& Intensive Care, 19, 348-351. http://www.apicareonline.com/index.php/APIC/article/download/366/352

[2] Blanco, R. (2011) The "Pecs Block": A Novel Technique for Providing Analgesia after Breast Surgery. Anaesthesia, 66, 847-848. https://doi.org/10.1111/j.1365-2044.2011.06838.x

[3] Battista, C. and Krishnan, S. (2020) Pectoralis Nerve Block. StatPearls Publishing, Treasure Island. https://www.ncbi.nlm.nih.gov/books/NBK547691

[4] Kulkarni, M., Diwan, S. and Nair, A. (2020) Failure of PECS 2 Block and a Numb Hand!! Saudi Journal of Anaesthesia; Riyadh, 14, 139-140. 
https://search.proquest.com/openview/d48267695677f8b8085f16a30a83bff2/1?pq-or igsite $=$ gscholar $\& \mathrm{cbl}=226459$

[5] Eldeen, H.M.S. (2016) Ultrasound Guided Pectoral Nerve Blockade versus Thoracic Spinal Blockade for Conservative Breast Surgery in Cancer Breast: A Randomised Controlled Trial. Egyptian Journal of Anaesthesia, 32, 29-35.

https://doi.org/10.1016/j.egja.2015.08.005

[6] Goswami, S., Kundra, P. and Bhattacharyya, J. (2017) Pectoral Nerve Block1 versus Modified Pectoral Nerve Block2 for Postoperative Pain Relief in Patients Undergoing Modified Radical Mastectomy: A Randomized Clinical Trial. British Journal of Anaesthesia, 119, 830-835. https://doi.org/10.1093/bja/aex201 https://academic.oup.com/bja/article-abstract/119/4/830/4157329

[7] Jin, Z., Li, R., Gan, T.J., He, Y.H. and Lin, J. (2020) Pectoral Nerve (PECs) Block for Postoperative Analgesia-A Systematic Review and Meta-Analysis with Trial Sequential Analysis. International Journal of Physiology, Pathophysiology and Pharmacology, 12, 40-50. https://www.ncbi.nlm.nih.gov/pmc/articles/PMC7076325

[8] Bashandy, G.M.N. and Abbas, D.N. (2015) Pectoral Nerves I and II Blocks in Multimodal Analgesia for Breast Cancer Surgery: A Randomised Clinical Trial. Regional Anesthesia \& Pain Medicine, 40, 68-74. https://doi.org/10.1097/AAP.0000000000000163

[9] Huan, S., Deng, Y., Wang, J., Ji, Y. and Yin, G. (2020) Efficacy and Safety of Paravertebral Block versus Intercostal Nerve Block in Thoracic Surgery and Breast Surgery: A Systematic Review and Meta-Analysis. PLoS ONE, 15, e0237363. https://doi.org/10.1371/journal.pone.0237363

[10] Blanco, R., Fajardo, M. and Parras Maldonado, T. (2012) Ultrasound Description of Pecs II (Modified Pecs I): A Novel Approach to Breast Surgery. Revista Española de Anestesiología y Reanimación, 59, 470-475. https://doi.org/10.1016/j.redar.2012.07.003

[11] Dube, M., Wu, J., Sharma, R., Chang, Y. and Makam, K. (2021) Intra-Operative Pectoral Nerve Block under Direct Vision-Does It Save Theatre Time for Breast Surgery? European Journal of Surgical Oncology, 47, e36-e37.

[12] Goswami, S. and Bhattacharya, J. (2016) Abstract PR487: Pec1 and Pec2 Block under Direct Vision for Postoperative Analgesia for Modified Radical Mastectomy-A Randomized Clinical Trial. Anesthesia \& Analgesia, 123, 617-618. https://journals.lww.com/anesthesia-analgesia/Fulltext/2016/09002/Abstract_PR487 _Pec1_And_Pec2_Block_Under_Direct.465.aspx https://doi.org/10.1213/01.ane.0000492872.96241.83

[13] Haydon, N.B., Van Der Rijt, R., Downs, C. and Buckland, G. (2016) A Novel Technique of Intraoperative Lateral Pectoral Nerve Block during Subpectoral Breast Implant Placement. Plastic and Reconstructive Surgery_Global Open, 4, e646. https://www.ncbi.nlm.nih.gov/pmc/articles/PMC4874290

[14] Shah, S.B., Hariharan, U. and Bhargava, A.K. (2018) Recent Trends in Anaesthesia and Analgesia for Breast Cancer Surgery. Trends in Anaesthesia and Critical Care, 20, 11-20. https://www.sciencedirect.com/science/article/pii/S2210844017303416 https://doi.org/10.1016/j.tacc.2018.03.001

[15] Macchi, V., Tiengo, C., Porzionato, A., et al. (2007) Medial and Lateral Pectoral Nerves: Course and Branches. Clinical Anatomy, 20, 157-162.

https://doi.org/10.1002/ca.20328

[16] Jaspars, J.J.P., Posma, A.N., Van Immerseel, A.A.H. and Gittenberger-de Groot, A.C. (1997) The Cutaneous Innervation of the Female Breast and Nipple-Areola 
Complex: Implications for Surgery. British Journal of Plastic Surgery, 50, 249-259. https://doi.org/10.1016/S0007-1226(97)91155-3

[17] Blanco, R. (2011) The "Pecs Block": A Novel Technique for Providing Analgesia after Breast Surgery. Anaesthesia, 66, 847-848.

https://doi.org/10.1111/j.1365-2044.2011.06838.x

[18] Versyck, B., van Geffen, G.J. and Van Houwe, P. (2017) Prospective Double Blind Randomised Placebo-Controlled Clinical Trial of the Pectoral Nerves (Pecs) Block Type II. Journal of Clinical Anesthesia, 40, 46-50.

https://doi.org/10.1016/j.jclinane.2017.03.054

[19] Hards, M., Harada, A., Neville, I., et al. (2016) The Effect of Serratus Plane Block Performed under Direct Vision on Postoperative Pain in Breast Surgery. Journal of Clinical Anesthesia, 34, 427-431. https://doi.org/10.1016/j.jclinane.2016.05.029 